\title{
PENERAPAN PALI DALAM RITUAL TIWAH DAYAK NGAJU
}

\section{PALI IN THE IMPLEMENTATION OF THE DAYAK NGAJU TIWAH RITUAL}

\section{Satriya Nugraha ${ }^{\text {** }}$ \\ Theresia Dessy \\ Wardani $^{2}$}

\author{
*IFakultas Hukum Universitas \\ PGRI Palangka Raya, Palangka \\ Raya, Kalimantan Tengah, \\ Indonesia. \\ 2FKIP Universitas PGRI \\ Palangka Raya, Palangka Raya, \\ Kalimantan Tengah, Indonesia \\ *email: nugraha.str@gmail.com
}

Kata Kunci:

Ritual Tiwah

Dendat Adat

Dayak Ngaju

\section{Keywords:}

Tiwah Ritual

Customary Fine

Dayak Ngaju

\section{Accepted}

Maret 202I

Published April 2021

\begin{abstract}
Abstrak
Penelitian ini bertujuan untuk mendeskripsikan ragam pali dan denda pali dalam ritual Dayak Ngaju Tiwah. Metode yang digunakan adalah metode kualitatif dengan model pendekatan budaya dengan mengumpulkan data berupa kata, gambar, dan bukan angka dari studi pustaka, wawancara, catatan lapangan, foto, dan video dengan menggunakan teknik pengumpulan data berupa reduksi data, penyajian data. dan menyimpulkan. Hasil yang diperoleh adalah bahwa dalam ritual tiwah terdapat pembatas adat yang disebut Hinting Pali, yang tidak dapat dilanggar oleh beberapa jenis pali atau pantangan seperti pali sayur, pali hewan, pali ikan, dan sikap / perilaku pali. Jika ada pelanggaran pali dalam ritual tiwah, denda yang diberikan adalah mengganti dua kali lipat biaya tiwah yang telah dikeluarkan oleh anggota ritual tiwah. Penelitian ini hanya membahas pali dalam ritual tiwah masyarakat adat Dayak Ngaju. Kedepannya, penelitian ini diharapkan dapat menjadi dasar penelitian tentang pali dalam ritual dan upacara lainnya dalam budaya masyarakat adat Dayak Ngaju Kalimantan Tengah.
\end{abstract}

\begin{abstract}
This study aims to describe the form of the pali type and the pali fine in the Dayak Ngaju Tiwah ritual. The method used is a qualitative method with a cultural approach model by collecting data in the form of words, pictures, and not numbers from literature studies, interviews, field notes, photos, and videos using data collection techniques such as data reduction, presentationi data and concluding. The results obtained are that in the tiwah ritual, there is a custom barrier called Hinting Pali, which cannot be violated by several types of pali or taboos such as vegetable pali, animal pali, fish pali, and pali attitude/behavior. If there is a violation of the pali in the tiwah ritual, the fine given is to replace twice the cost of the tiwah that has been incurred by the member of the tiwah ritual. The research only discusses pali in the tiwah ritual of the Dayak Ngaju indigenous people. In the future, this research is expected to become the basis for research on pali in rituals and other ceremonies in the culture of the Dayak Ngaju indigenous people of Central Kalimantan.
\end{abstract}

(C) 2021 The Authors. Published by Institute for Research and Community Services Universitas Muhammadiyah Palangkaraya. This is Open Access article under the CC-BY-SA License (http://creativecommons.org/licenses/by-sa/4.0/).

\section{PENDAHULUAN}

Dayak Ngaju merupakan suku asli dan terbesar yang menempati provinsi Kalimantan Tengah (Sukiada 2016). Ada banyak sekali upacara ritual yang dilakukan oleh masyarakat Dayak Ngaju. Ritual adat yang biasa diselengarakan oleh para penganutnya (suku Dayak Ngaju) antara lain; upacaratiwah, upacara manajah antang, upacara perkawinan, kematian/balian, upacara mapalas/pengobatan, upacara kehamilan, upacara sangiang, upacara menetek pantan, upacara mamapas lewu dan laluhan (Kuenna 20I5).
Ritual tiwah dilakukan untuk mengantarkan arwah (liaw) orang yang sudah meninggal ke surga (lewu tataw) atau negeri roh (lewu liaw) dengan memindahkan tulang belulang orang yang sudah meninggal ke dalam sandung yaitu bangunan yang berukiran indah (Hanifi 2016). Tiwah merupakan proses pemindahan tulang belulang/tengkorak anggota keluarga yang telah lama meninggal dari kuburan untuk diletakkan kedalam sandung (Anwari 20I7).

Upacara Tiwah tidak saja menarik untuk masyarakat Kalimantan Tengah. Banyak wisatawan domestik dan wisatawan internasional yang ingin melihatnya. Namun, 
perlu diperhatikan bahwa ada sejumlah pantangan saat menyaksikan upacara Tiwah. Aturan ini disebut pali, yang jika dilanggar akan mendapat jipen atau denda. Pendatang ataupun tamu diharuskan untuk mentaati adat dan jangan sampai melanggar pali, seperti mencuri, merampas dan melecehkan anak gadis dan isteri orang, menghina dan lain-lain. Tamu sangat dihormati oleh warga Dayak. Oleh sebab itu, hendaknya pendatang/tamu diharapkan juga menghormati tata krama adat mereka (Liadi 2017).

Koentjaraningrat menyatakan (dalam Inrevolzon 2013) bahwa kebudayaan adalah keseluruhan manusia dari kelakuan dan hasil kelakuan yang teratur oleh tata kelakuan yang harus didapatnya dengan belajar dan yang semuanya tersusun dalam kehidupan masyarakat. Pembagian budaya juga dapat dibuat dengan suatu pembagian yang lebih sederhana, yakni dengan memandang kebudayaan sebagai (I) pengatur dan pengikat masyarakat, (2) hal-hal yang diperoleh manusia melalui belajar/pendidikan (nurture), (3) pola kebiasaan dan perilaku manusia, dan (4) sistem komunikasi yang dipakai masyarakat untuk memperoleh kerjasama, kesatuan, dan kelangsungan hidup masyaraka (Devianty 2017).

Definisi kebudayaan menurut ahli Antropologi, khususnya Koentjaraningrat (dalam Bukit 2019) yang dapat dikatakan sebagai ahli Antropologi terkemuka di Indonesia: "kebudayaan adalah keseluruhan sistem gagasan, tindakan dan hasil karya manusia dalam rangka kehidupan masyarakat, yang dijadikan milik dari manusia dengan belajar."

Kebudayaan itu ternyata sangat luas, dalam dan tinggi, karena mencakup semua yang ada di dalam fikiran, tindakan dan hasil karya manusia dalam rangka kehidupannya di dalam kehidupan sosial, budaya dan alamnya. Dengan demikian bisa juga dikatakan, bahwa kebudayaan itu adalah strategi hidup manusia di dalam masyarakatnya, sehingga dia dapat bertahan untuk hidup dilingkungan sosial, budaya dan alamnya serta strategi itu harus dipelajari, sehingga manusia dapat menguasainya. Di mana semuanya itu, dapat dijadikan milik oleh manusia secara terus menerus atau turun temurun melalui proses belajar.

Kebudayaan atau pun yang disebut peradaban, mengandung pengertian yang luas, meliputi pemahaman perasaan suatu bangsa yang kompleks, meliputi pengetahuan, kepercayaan, seni, moral, hukum, adat istiadat (Kebiasaan), dan pembawaan lainnya yang diperoleh dari anggota masyarakat. Adat merupakan wujud dari kebudayaan. Adat adalah aturan, kebiasaankebiasaan yang tumbuh dan terbentuk dari suatu masyarakat atau daerah yang dianggap memiliki nilai dan dijunjung serta dipatuhi masyarakat pendukungnya, "Adat adalah kebiasan yang normative dan dipertahkan oleh masyarakat, maka walaupun adat tidak terus berulang, pada saat tertentu akan terus berulang dan harus (Dova, Yanzi, and Nurmalisa 2016).

Definisi istiadat menurut Iskandar (dalam Surya 2017) adalah meliputi adat kebiasaan, resam, dan juga dapat diartikan sebagai upacara dan peralatan. Apabila adat dan istiadat digabungkan, maka ia membawa pengertian suatu peraturan yang diikuti dalam masyarakat danjuga kebiasaankebiasaan yang dipakai disamping terdapatnya upacara-upacara dan peralatan tertentu dalam menjalankan peraturan-peraturan dimaksud. Adat istiadat menampakkan satu pola perlakuan anggota masyarakat didalam sesebuah kelompok, wilayah atau negeri. Adat istiadat lebih merupakan kebiasaan yang disukai dan diakui oleh masyarakat.Selanjutnya berbagai definisi diatas dapatlah dikatakan bahwa adat-istiadat merupakan suatu peraturan yang terdapat dalam masyarakat yang telah diakui dan dipatuhi oleh anggota masyarakat berkenaan.

Keanekaragaman budaya dan tradisi melahirkan masyakat adat. Di dalam masyarakat adat terdapat hukum adat. Menurut Hukum adat merupakan hukum yang lahir dari nilai-nilai budaya masyarakat adat sebagai cerminan dari sesuatu yang dianggap benar, 
patut dan baik dalam menata hubungan-hubungan mereka dengan lingkungan sosialnya maupun lingkungan alam fisiknya seperti tanah. Dalam menata hubungan sosial dan fisik telah melahirkan pranatapranata hukum adat seperti hukum kekerabatan (kinship), hukum perkawinan, hukum waris, hukum delik, hukum tanah dan sebagainya. Apa yang dianggap benar, patut dan baik itu terus berkembang sesuai dengan perkembangan sistem budaya masyarakat adat. Perkembangan tersebut bersifat evolusioner sesuai dengan konteks kebutuhan dan tuntutan masyarakatnya. Perkembangan tersebut berbeda-beda antara lingkungan masyarakat adat yang satu dengan lainnya (Syamsudin 2008).

Arliman mengemukakan bahwa hukum adat merupakan hukum yang tidak tertulis. Hukum adat pada hakekatnya adalah tradisi juga, yaitu praktek kehidupan warga masyarakat dalam pergaulan hidup bermasyarakat yang dianggap benar oleh norma-norma yang diciptakannya sendiri dan diberi daya memaksa dengan sanksi bagi yang melanggarnya, norma yang dipraktekkan tersebut berasal dari warisan masa lalu yang selalu diperbaharui dengan diadakan reinterpretasi agar sesuai dengan tuntutan jaman dan keadaan serta perubahan masyarakat (Arliman 2018).

Masyarakat adat memiliki kebiasa-kebiasaan. Kebiasaan ini dapat berupa adat dalam upacara ritual. Secara etimologis, upacara ritual dapat dibagi atas dua kata yakni upacara dan ritual. Upacara adalah suatu kegiatan yang dilaksanakan sekelompok orang serta memiliki tahapan yang sudah diatur sesuai dengan tujuan acara. Sedangkan yang dimaksud dengan ritual adalah suatu hal yang berhubungan terhadap keyakinan dan kepercayaan spritual dengan suatu tujuan tertentu (Situmorang dalam Ngare 2014). Situmorang dapat menyimpulkan bahwa pengertian upacara ritual adalah sebuah kegiatan yang dilakukan sekelompok orang yang berhubungan terhadap keyakinan dan kepercayaan spritual dengan suatu tujuan tertentu.
Pelaksanaan ritualnya memiliki makna sosial yang amat tinggi. Sebagian pelakunya ada yang sadar bahwa ini adalah "perintah" atau tuntutan dan atas keyakinannya, tetapi ada juga yang melaksana-kannya karena sudah menjadi tradisi atau kebiasan anggota masyarakatnya. Ritus-ritus dan upacara religi pada dasarnya berfungsi sebagai penyemanga tkehidupan. Penyemangat dalam bentuk ritus-ritus juga biasa diberikan kepada tahap-tahap pertumbuhan individu seperti lahir, kanak-kanak, menikah, menjadi tua, hingga meningggal dunia. itus dan upacara itu dibagi menjadi tiga, yakni pertama, perpisahan (sparation), ritus ini dalam bentuk upacara kematian. Kedua, peralihan (marge), adalah ritus yang berkaitan dengan peralihan tahap seperti upacara hamil tujuh bulan atau mithoni. Ketiga, integrasi. Upacara kegiatan ini seperti dalam acara selamatan kelahiran, pernikahan, dan pergantian musim (Chakim 20I5).

Salah satu ritual yang ada di masyarakat Dayak Ngaju adalah ritual tiwah. Menurut Tjilik Riwut (dalam Helim and Syahriana 2019) tiwah adalah upacara sakral terbesar untuk mengantarkan jiwa atau arwah anggota keluarga yang telah meninggal dunia menuju tempat yang dituju, yaitu lewu tatau (surga), terletak di langit ketujuh. tiwah adalah upacara kematian tingkat terakhir untuk menyucikan para arwah keluarga yang telah meninggal dunia agar dapat menyatu dengan Ranying Hatalla (Tuhan) sekaligus menyucikan anak keturunan yang masih hidup agar mencapai hidup yang sejati, damai, bahagia, dan harmonis.

Tiwah bertujuan untuk menyucikan, membebaskan, dan menyempurnakan arwah orang-orang yang telah meninggal dunia dalam melakukan perjalanannya menuju lewu tatau (Surga). Berkat tiwah, arwah akan menempuh perjalanan yang lurus tanpa halangan, sehingga ia mendapatkan kehidupan yang tenteram dan damai di alam Sang Kuasa. Tujuan utamanya adalah agar arwah tersebut dapat menyatu dengan Ranying Hatalla. Di sisi lain, tiwah bertujuan untuk melepaskan 
kesialan bagi keluarga yang ditinggalkan. Tiwah juga bermakna melepaskan ikatan status janda atau duda bagi pasangan berkeluarga, sehingga setelah upacara tiwah tersebut mereka dibolehkan menentukan pasangan hidup selanjutnya atau tetap memilih untuk tidak menikah lagi.

Pelaksanaan ritual tiwah sangatlah kompleks. Dalam pelaksanaannya terdapat pali dan jipen (singer adat) yang merupakan salah satu bentuk hukum adat yang berlaku di masyarakat Dayak Ngaju yang diterapkan secara umum kepada para pengunjung yang datang untuk menyaksikan upacara tiwah. Pali yang berlaku secara sosiologis di masyarakat dan juga berlaku secara yuridis dengan adanya Peraturan Daerah Provinsi Kalimantan Tengah Nomor 10 tahun 2010 Tentang Perubahan Atas Peraturan Daerah Provinsi Kalimantan Tengah Nomor 16 Tahun 2008 Tentang Kelembagaan Adat Dayak di Kalimantan Tengah. Adat atau kebiasaan yang terjadi dalam masyarakat Dayak dan berlaku berdasarkan pengalaman hidupmasyarakat Dayak membentuk norma atau aturan perilaku dengan falsafah Huma betang (Pelu and Tarantang 2018).

Bahadat bukan hanya mengerti dan memahami hukum adat dan hukum pali dengan baik, namun nyata terlihat dalam tindakan sehari-hari. Ranying Hatalla atau Allah Yang Maha Kuasa turut serta mengawasi setiap tindakan yang dilakukan oleh para pemimpin, sehingga kendali diri pegang peranan dalam melaksanakan tugas dan tanggung jawabnya. Berani berlaku tidak adil konsekwensinya hukuman akhirat akan diterima setelah kematian terjadi (Apandie and Ar 2019).

Bagi umat manusia tidak ada tempat yang bebas dari hadat dan tidak ada waktu tanpa hadat. Hadat memerintah seluruh kehidupan, dan seseorang tidak dapat mengambil langkah, dapat memulai tetapi tidak dapat melanjutkan, tanpa bentuk, dan rangkaian keseluruhan yang ditentukan oleh hadat. Hadat adalah penuntun untuk menjalani hidup, dan seseorang harus diarahkan olehnya (dan dapat mengarahkan dirinya sendiri, jika tidak maka dia tersesat dari jalan yang benar (Natalia, Tarantang, and Astiti 2020).

Peneliti sebelumnya hanya membahas tentang proses ritual tiwah, unsur-unsur ritual tiwah, dan makna arsiteknya. Upacara Tiwah adalah salah satu tradisi keagamaan yang telah ada secara turun temurun dan menjadi kekayaan tersendiri bagi bangsa Indonesia. Suku Dayak telah menghayati dan melaksanakan tradisi upacara Tiwah hingga saat ini. Seperti penelitian (Saputri et al. 2016) dengan judul "Perancangan Film Dokumenter Tradisi Keagamaan Suku Dayak di Kalimantan Tengah”. Dalam penelitian ini dirancang pembuatan film dokumenter yang singkat namun mencakup semua proses ritual tiwah.

Terdapat hal yang menarik dalam pelaksanaan acara ritual tiwah yaitu adanya permainan usik liaw. Usik liaw adalah bagian terpenting dan memiliki nilai sakral. Melalui pelbagai jenis permainan yang dimainkan dalam usik liaw memiliki tujuan dan makna tersendiri dan satu bagian dari seluruh bagian acara ritual tiwah. Tradisi usik liaw adalah bagian integral dari acara tiwah itu sendiri dimaksudkan untuk kemashyuran bagi para roh di alam baka. Hal ini merupakan hasil penelitian dari (Achmadi 2016) dengan judul penelitian "Penegakan Hukum Pidana Terhadap Praktek Perjudian dalam Ritual Tiwah Di Kabupaten Kapuas".

Arsitektur dan makna dalam ritual tiwah juga diteliti. Seperti (Iban and Elfrida 20I7), dengan penelitian yang berjudul judul "Arsitektur Religi Pesta Tiwah Dayak Ngaju sebagai Daya Tarik Wisuta Budaya Di Kalimantan Tengah". Dalam tulisannya itu menggambarkan Arsitektur religi dalam Pesta Tiwah merupakan pencampuran antara aspek-aspek yang berasal dari ruang transenden dunia atas dan dunia bawah, di mana keduanya merupakan bagian dari konsep Celestial Realm, yaitu aspek-aspek yang terkait dengan konsep teologis Kaharingan dan kosmologis Dayak Ngaju, dan aspek-aspek yang berasal dari kehidupan manusia di ruang realitas atau Terrestrial Realm. 
Eksistensi pilosofi dari ritual tiwah juga pernah diteliti sebelumnya oleh (Gunawan et al. 2018) dengan judul "The Existence and Philosophy Of Tiwah In Palangka Raya City”. Dalam penelitian tersebut dijelaskan bahwa Ritual Tiwah memiliki fungsi sebagai tujuan akhir umat hindu kaharingan untuk mencapai surga atau moksa. Lebih lanjut dijelaskan pula tentang fungsi ritual tiwah bagi umat hindu kaharingan yang berfungsi sebagai "tiang kematian terakhir untuk mencapai surga". Berdasarkan hal tersebut, dalam hal ini fungsi upacara atau ritual tiwah adalah sebagai bentuk penghormatan, pengabdian, dan rasa syukur bagi umat hindu kaharingan terhadap kerabat, keluarga, orang tua atau kerabat keluarga.

Warga Dayak Ngaju muslim pada dasarnya masih sangat menghargai kebudayaan dan juga sangat menghormati leluhur mereka, karena dalam kehidupan mereka sangat percaya terhadap leluhur mereka, seperti mengikuti pelaksanaan upacara Tiwah ada yang masih merasa berkewajiban melaksanakan upacara Tiwah terhadap keluarganya yang sudah meninggal. Hal ini sejalan dengan hasil penelitian (Sanawiah and Abdalla 2017) dengan judul "Hukum Keikutsertaan Warga Dayak Ngaju Muslim dalam Pelaksanaan Upacara Tiwah". Hal yang sama juga diteliti oleh (Helim, 2019) dengan judul "Keikutsertaan Masyarakat Muslim dalam Upacara Tiwah Agama Hindu Kaharingan di Kota Palangka Raya”.

Begitu banyak sekali unsur-unsur dalam pelaksanaan ritual tiwah, diantaranya tumbuhan ritual, hewan kurban, sangkaraya, sapundu. Salah satu unsur dalam ritual tiwah juga pernah diteliti oleh (Norhalisa, Lion, and Dotrimensi 2020) dengan judul “Makna Sapundu bagi Masyarakat Agama Hindu Kaharingan dalam Upacara Tiwah Di Desa Tumbang Manjul Kecamatan Seruyan Hulu Kabupaten Seruyan”. Makna dari patung sapundu dalam ritual tiwah bagi masyarakat Dayak Ngaju adalah sebagai perantara membantu mengantarkan roh keluarga yang meninggal menuju lewu liaw lewu tatau sanang atau surga.
Berdasarkan beberapa penelitian di atas, terlihat jelas belum ada satu penelitian pun yang membahas tentang pali dalam ritual tiwah. Hal inilah yang menjadi pembeda anatara penelitian ini dengan penelitian sebelumnya. Hal ini juga menjadi kebahruan dalam penelitian tiwah suku dayak ngaju Kalimantan Tengah.

Pali atau pantangan tidak hanya ada di masyarakat Dayak Ngaju Kalimantan Tengah, namun juga ada di masyarakat suku lain. Pali atau pantangan yang ada di daerah Jawa terdapat ritual warok Ponorogo. Seorang warok dalam melakukan lakon harus menghindari sirikan (pantangan) yang jika dilanggar maka hilanglah daya mistiknya. Berdasarkan hasil penelitian (Taufiq 2013) pantangan-pantangan yang harus ditinggalkan sama dengan norma-norma jawa dikenal dengan molimo yaitu maling (mencuri), madat (candu), main (berjudi), minum (minum-minuman keras/mabuk), madon (mempermainkan wanita). Didalam kepercayaan warok ada anggapan bahwa wanita sebagai sirikan (tabu)yang harus dijauhi, sebab menurut mereka wanita mempunyai daya tarik yang mampu melemahkan kekuatan batin dan daya mistik yang telah dimiliki, sehingga banyak diantara mereka yang menunda masa perkawinannya hingga usia tua, sebagai gantinya mereka memilih hidup dengan gemblak seorang laki-laki tampan dalam waktu yang telah disepakati. Selain lima diatas ditambah dua macam lagi yaitu mateni (membunuh) dan madani (seperti menipu, ngrasani (menjelekkan orang lain dan sebagainya. Jadi menurut ajaran warok apabila manusia sudah bisa melaksanakan norma-norma yang ditetapkan dia akan mencapai kesempurnaan hidup dan terjaga daya mistiknya.

Pantangan dalam ritual juga ada di masyarakat Bajo Gorontalo. Dalam ritual Kapontaso pada sistem perladangan masyarakat etnik Muna (Si 2016) Sebelum masyarakat berladang, masyarakat harus memperhatikan pantangan yang di daerah sana dikenal dengan sebutan parika. Dalam pemeriksaan keadaan tanah ini, ada pantangan yang dijadikan acuan untuk 
menentukan lahan ladang baik atau buruknya keadaan tanah. Pantangan yang dimaksud adalah (I) apabila dalam kebun

sering didengarkan tanda-tanda makhluk halus (misalnya terdengar suara aneh di atas pohon besar), maka ladang tersebut bisa dibatalkan karena ladang tersebut ada penunggunya. Apabila ditemukan pantangan tersebut, maka ladang yang akan digarap bisa dibatalkan. Karena apabila petani tetap mengolahnya akan membahayakan mereka. Apabila pantangan tersebut tidak ditemukan maka dilanjutkan kegiatan persiapan ladang.

Masyarakat Dayak Salako, Sambas Kalimantan Barat, juga terdapat pantangan dalam ritual naah padi. Sistem berladang padi masyarakat Dayak Salako tidak dilakukan sesuka hati tetapi ada beberapa aturanaturan atau pantangan yang harus ditaati. Naah padi salah satu ritual yang wajib dilakukan pada proses berladang padi. Apabila ritual naah padi sudah dilaksankan maka ada beberapa amaik yang tidak boleh dilanggar. Amaik merupakan aturan-aturan adat yang berbentuk pantangan dan larangan dalam aktivitas berladang padi masyarakat Dayak Salako yang lebih di kenal dengan istilah amaik padi. amaik padi meliputi amaik ujaran, amaik tindakan, amaik mitos, amaik ritual adat, amaik nasihat. Dalam amaik ritual adat menanam padi, pantangan yang tidak boleh dilanggar seperti dalam melaksanakan ritual tidak diperbolehkan menggunakan ayam jantan. Jika pantangan ini dilanggar maka berladangnya dapat gagal pada masa panennya, dan padi akan diserang hama (lyon 2018).

Berdasarkan wawancara dengan Damang kepala adat Jekan Raya kota Palangka Raya Bapak Kardinal Tarung, "pali adalah pantangan yang harus ditaati setiap orang ketika melakukan ritual. Jika pali atau pantangan ini dilanggar selama ritual dilaksanakan, maka akan dikenakan singer adat atau sanki atau denda adat”.

Fokus masalah dalam penelitian ini, yaitu wujud jenis pali dan denda pali pada ritual tiwah suku Dayak Ngaju.

Tujuan dari penelitian ini adalah untuk mendeskripsikan wujud jenis pali dan denda pali pada ritual tiwah suku Dayak Ngaju. Penelitian ini penting untuk dilakukan karena belum adanya penelitian yang membahas secara fokus tentang pali dan denda pali pada ritual tiwah suku Dayak Ngaju.

\section{METODOLOGI}

Metode penelitian yang digunakan dalam penelitian ini adalam metode kualitatif dengan model pendekatan kebudayaan. Dalam perspektif ini penafsiran terhadap peristiwa-peristiwa dalam kehidupan kebudayaan mempehitungkan dan menggambarkan pengertian baru untuk pembaca dan orang luar. Penelitian Kualitatif memiliki karakter, yaitu penelitian yang menggunakan manusia sebagai instrumennya, menggunakan metode pengamatan, wawancara, atau penelaah dokumen. Penelitian kualitatif mengumpulkan data secara deskriptif, serta menggunakan analisis data secara induktif (Moleong 2012a).

Data kualitatif yang dikumpulkan adalah berupa katakata, gambar, dan bukan angka-angka. Data yang diperoleh dalam penelitian ini berasal dari hasil studi pustaka, wawancara, catatan lapangan, foto, dan video. Sumber data seperti yang diuraikan oleh (Sugiyono 2016) dalam penelitian kualitatif yaitu tempat, pelaku, dan aktivitas. Pada penelitian kualitatif peneliti memasuki situasi sosial tertentu, melakukan observasi dan wawancara kepada orang-orang yang dipandang tahu tentang situasi sosial. Sehingga, sumber data dalam penelitian ini adalah informan yang dikategorikan sebagai masyarakat Kalimantan Tengah yang terdiri dari basir, mantir, dan damang yang ada di kecamatan di kota Palangka Raya.

Teknik pengumpulan data dengan langka-langkah pengamatan, yaitu pengamat sebagai pemeran serta, yaitu secara terbuka diketahui oleh umum. Wawancara, yaitu menggunakan metode wawancara kepada informan dengan tujuan peneliti akan mendapat informasi mengenai masalah yang akan diteliti, dan dokumentasi. Peneliti memberikan stimulasi 
(rangsangan) pada informan untuk memunculkan gejala kebahasaan yang diharapkan peneliti. Teknik analisis data menggunakan metode perbandingan tetap (Grounded Research) seperti yang dikemukakan oleh Moleong (Moleong 20I2b).

a. Reduksi Data

I) Melakukan identifikasi pada setiap satuan/unit dari data yang memiliki jenis pali dan denda pali dalam ritual tiwah.

2) Mengkodifikasi yaitu memberikan kode sesuai dengan kategori yang berkaitan dengan jenis pali dan denda pali dalam ritual tiwah

3) Memilah data setiap satuan ke dalam bagianbagian yang memiliki kesamaan.

4) Membuat label pada setiap kategori data yang ditemukan.

5) Mencari kaitan antar satu kategori dengan kategori lainnya dalam data.

6) Mengklasifikasi yaitu pengelompokan data sesuai dengan fokus kajian penelitian.

b. Penyajian Data

I) Menginterpretasi yaitu melakukan analisis secara deskriptif tentang jenis pali dalam ritual tiwah.

2) Menginterpretasi yaitu melakukan analisis secara deskriptif tentang denda pali dalam ritual tiwah.

c. Penarikan Kesimpulan

I) Merumuskan simpulan berdasarkan hasil analisis yang telah diinterpretasi.

2) Memberikan simpulan umum tentang hasil deskripsi dan analisis.

\section{HASIL DAN PEMBAHASAN}

Jenis Pali dalam ritual tiwah suku Dayak Ngaju

Di Indonesia, salah satu hukum yang merupakan pencerminan kepribadian bangsa adalah hukum adat, yang merupakan penjelmaan jiwa bangsa tersebut dari abad ke abad. Adat yang dimiliki oleh daerah-daerah adalah berbeda-beda, meskipun dasar serta sifatnya satu yaitu ke-Indonesiaannya. Oleh karena itu adat bangsa Indonesia dikatakan merupakan Bhinneka Tunggal Ika, yang artinya berbedabeda, tetapi tetap satu. Adat tersebut selalu berkembang dan senantiasa mengikuti perkembangan masyarakat dan erat hubungannya dengan tradisi rakyat. Dengan demikian adat merupakan endapan kesusilaan dalam masyarakat, yang kebenarannya telah mendapat pengakuan umum dalam masyarakat tersebut (Susylawati 2013).

Hukum adat yang berawal dari kebiasaan masyarakat juga terdapat pada setiap ritual adat suku Dayak Ngaju. Dalam ritual tiwah begitu banyak unsur yang mengikat di dalamnya. Ritual tiwah tidak hanya sekedar ritual pengantaran roh menuju surga bagi masyarakat hindu kaharingan, melaikan juga pesata ucapan syukur bagi kelurga terhadap para kerabat dan masyarakat. Tiwah menurut masyarakat Kalimantan Tengah adalah sebuah aturan atau perbuatan/adat (Wirna 2018). Pada pelaksanaan ritual tiwah seperti yang dikaji dalam penelitian ini. Terdapat beberapa pali yang disepakati oleh masyarakat secara turun temurun. Pali merupakan salah satu bentuk hukum adat yang berlaku di masyarakat Dayak Ngaju yang diterapkan secara umum kepada para pengunjung yang datang untuk menyaksikan upacara tiwah. Pali ini dibagi menjadi beberapa jenis, yaitu pali sayuran, pali hewan, pali ikan, dan pali sikap perilaku.

Tabel I. Jenis Pali dalam Ritual Tiwah

\begin{tabular}{|c|c|c|}
\hline No & Jenis Pali & Unsur Pali \\
\hline \multirow[t]{8}{*}{$\mathrm{I}}$. & Sayur-Sayuran & Ujau (rebung) \\
\hline & & 2. Kulat (jamur) \\
\hline & & Bajei papalek penyak (paku) \\
\hline & & $\begin{array}{l}\text { 4. Kalakai batuyang bintang } \\
\text { (pakis) }\end{array}$ \\
\hline & & Botong (Labu Putih) \\
\hline & & 6. Tungkul munus \\
\hline & & Pisang) \\
\hline & & $\begin{array}{l}\text { 7. Singkah uhut tanjung (umbut } \\
\text { rotan) }\end{array}$ \\
\hline \multirow[t]{5}{*}{2.} & Hewan & $\begin{array}{ll}\text { I. Palanduk simping taliwu } \\
\text { (kancil) }\end{array}$ \\
\hline & & 2. Karahau tunjang pahera (kijang) \\
\hline & & Bajang kalingkai lawung (rusa) \\
\hline & & $\begin{array}{l}\text { 4. Bawui sahempun bukit (babi } \\
\text { hutan) }\end{array}$ \\
\hline & & 5. Panganen/depung (ular sawah) \\
\hline
\end{tabular}




\begin{tabular}{|c|c|c|c|}
\hline \multirow[t]{3}{*}{3.} & Ikan & $\begin{array}{l}\text { I. } \\
2 . \\
3 . \\
4 .\end{array}$ & $\begin{array}{l}\text { Manjuhan (jelawat) } \\
\text { Kalakasa (arwana) } \\
\text { Tahuman (gabus) } \\
\text { Jalujung (tususk samben) }\end{array}$ \\
\hline & & 5. & $\begin{array}{l}\text { Tampala leleng hempeng } \\
\text { (sambaling) } \\
\text { Tatawun (karungkung sahep) }\end{array}$ \\
\hline & & $\begin{array}{l}7 . \\
8 .\end{array}$ & $\begin{array}{l}\text { Saluang renteng tantahan } \\
\text { (saluang bahandang) } \\
\text { Undang sahep sahep kumpang } \\
\text { (udang sungai) } \\
\text { Kelep bajuku (penyu) }\end{array}$ \\
\hline \multirow[t]{8}{*}{4.} & Sikap/perilaku & I. & $\begin{array}{l}\text { Tidak boleh ada pertengkaran } \\
\text { baik sesama keluarga maupun } \\
\text { orang lain. }\end{array}$ \\
\hline & & 2. & $\begin{array}{l}\text { Tidak boleh membawa } \\
\text { binatang yang memasuki lokasi } \\
\text { upacara ritual tiwah, sejenis } \\
\text { rusa dan babi hutan. }\end{array}$ \\
\hline & & 3. & $\begin{array}{l}\text { Tidak boleh membawa senjata } \\
\text { tajam kecuali } \\
\text { kepentingan upacara ritual } \\
\text { tiwah. }\end{array}$ \\
\hline & & 4. & $\begin{array}{l}\text { Tidak boleh mabuk- } \\
\text { mabukan/minuman keras }\end{array}$ \\
\hline & & & $\begin{array}{l}\text { beralkohol di lokasi ritual } \\
\text { tiwah berlangsung. }\end{array}$ \\
\hline & & 5. & $\begin{array}{l}\text { Tidak melakukan kawin lari ke } \\
\text { lokasi upacara tiwah } \\
\text { berlangsung. }\end{array}$ \\
\hline & & 6. & $\begin{array}{lcc}\text { Tidak boleh } & \text { mencuri } \\
\text { (manakau) di dalam lokasi } & \text { litual } & \text { tiwah } \\
\text { upacara } & \text { ritual } & \\
\text { berlangsung. } & & \end{array}$ \\
\hline & & 7. & $\begin{array}{l}\text { Tidak boleh menjual minuman } \\
\text { keras beralkohol di area } \\
\text { hinting pali. }\end{array}$ \\
\hline
\end{tabular}

Pali atau pantangan dalam ritual tiwah suku Dayak Ngaju ini berlaku bagi masyarakat tempat melaksanakan ritual tiwah. Pali ini juga berlaku bagi para pengunjung yang datang menyaksikan ritual tiwah. Pali ini berlaku selama tiwah berlangsung, dari awal dimulainya ritual tiwah hingga selesainya rangkaian ritual tiwah tersebut.

\section{Denda Pali dalam Ritual Tiwah Suku Dayak Ngaju}

Hukum adat juga sama halnya seperti hukum positif, yaitu sama-sama memiliki denda yang berupa sanksi bagi yang melanggarnya. Pali dalam ritual tiwah ini harus ditaati oleh masyarakat dan pengunjung yang datang selama ritual tiwah berlangsung. Biasanya ritual tiwah berlangsung selama empat puluh hari, dan selama itu juga pali itu berlaku. Denda adat ini disebut singer adat, yaitu sanksi adat ini dintanggu perorang bagi yang telah melanggarnya. Adapun denda adat yang diberlakukan bagi yang melanggari pali dalam ritual tiwah adalah mengganti dua kali dari biaya ritual tiwah yang telah dikeluarkan oleh seluruh anggota tiwah.

Zaman sekarang, ritual tiwah dilaksanakan secara berkelompok untuk menghemat biaya pelaksanaan ritual tiwah yang cukup besar dananya. Pali yang berupa makanan seperti sayuran, jenis ikan, jenis hewan ini berlaku bagi seluruh anggiota yang melaksanakan ritual tiwah. Selama pelaksanaan ritual tiwah, jenis sayur, ikan dan hewan itu tidak diperbolehkan untuk dimakan oleh pelaksana tiwah. Sedangkan pali untuk sikap dan perilaku berlaku bagi seluruh masyarakat baik anggota keluarga pelaksana maupun masyarakat di tempat pelaksaan ritual tiwah, dan pengunjung yang datang dari luar daerah untuk menyaksikan ritual tiwah.

Pada saat ritual tiwah berlangsung, dibuatkan hinting pali (portal adat). Hinting pali ini terbuat dari tali atau rotan yang diberi daun sawang sebagai pembatas tempat yang boleh dilalui dna tidak boleh dilalui untuk pali tertentu. Misalkan untuk binatang seperti babi hutan, rusa, kancil, kijang tidak diperbolehkan memasuki atau dibawa masuk secara sengaja melewati hinting pali. Hinting pali biasanya dibuat sepanjang seratus meter yang mengeliling daerah ritual tiwah. Sebagai contoh jika ada pengunjungyang berkelahi dengan sesama pengunjung dan meleawati hinting pali, maka pengunjung yang berkelahi tersebut dikanakan singer adat.

Hinting pali juga merupakan bagian ritual adat masyarakat Dayak Ngaju yang digunakan saat terjadi kasus konflik tanah adat dengan menutup lokasi tanah adat yang menjadi sengketa (Yuliana 2019). Hinting pali juga merupakan sebuah warisan para leluhur masyarakat Dayak dalam mempertahankan hak kepemilikannya yang diakui oleh pihak yang tidak bertanggung jawab (Usop 20I5). 


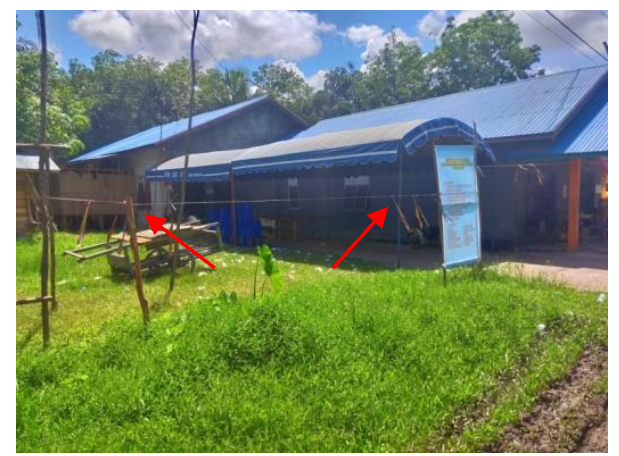

Gambar I. Tampak Samping Hinting Pali di Sekitar Area Ritual Tiwah

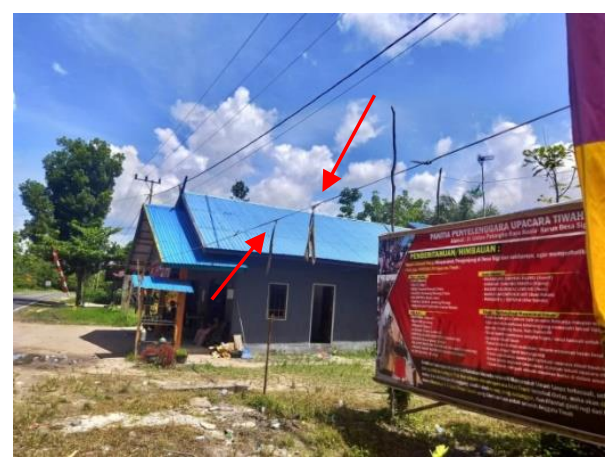

Gambar 2. Tampak Depan Hinting Pali di Sekitar Area Ritual Tiwah

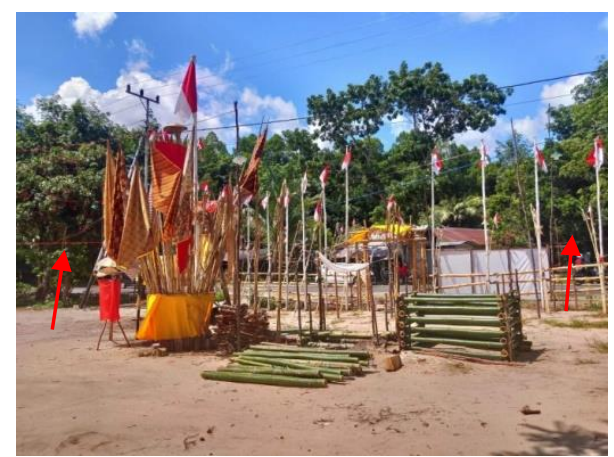

Gambar 2. Tampak Dalam Hinting Pali di Sekitar Area Ritual Tiwah

Ritual tiwah merupakan ritual yang sangat sakral bagi masyarakat Dayak Ngaju yang berkeyakinan kaharingan. Pada saat ritual ini dilaksanakan, para roh leluhur serta roh orang yang ditiwah (roh yang diantarkan ke lewu tataw atau surga) juga hadir di tempat ritual tiwah. Hal inilah yang membuat adanya pali atau pantangan saat ritual tiwah dilaksnakan. Pali atau pantangan ritual tiwah ini jika dilanggar akan mendatangkan kesiala, mala petaka, serta hal-hal yang buruk akan terjadi, baik untuk yang melakukan pantangan pali, bagi yang melaksanakan ritual tiwah,ataupun bagi yang hadir menyaksikan tiwah.

Pali atau pantangan hampir ada di setiap daerah dan Pali telah menjadi sebuah hukum tidak tertulis dan kebiasaan turun-temurun serta juga menjadi norma adat yang mengatur tentang kehidupan bermasyarakat dan berbudaya di Kalimantan Tengah.

\section{KESIMPULAN}

Ritual tiwah dilakukan untuk mengantarkan arwah (liaw) orang yang sudah meninggal ke surga (lewu tataw) atau negeri roh (lewu liaw) dengan memindahkan tulang belulang orang yang sudah meninggal ke dalam sandung. Tiwah menurut masyarakat Kalimantan Tengah adalah sebuah aturan atau perbuatan/adat. Dalam ritual tiwah terdapat beberapa jenis pali atau pantangan dan denda adat atau singer adat bagi yang melanggar pali tersebut. Jenis pali dalam ritual tiwah terdiri dari pali makanan, yaitu pali sayuran, pali hewan, dan pali ikan. Jenis pali makanan adalah pali yang didak boleh dimakan oleh anggota pelaksa ritual tiwah semala ritual tiwah berlangsung. Jenis pali yang lain, yaitu pali sikap atau perilaku. Pali sikap atau perilaku ini berlaku bagi anggota pelaksana tiah, masyarakat tempat tiwah berlangsung, dan juga pengunjung yang datang dari luar daerah yang menyaksikan ritual tiwah. Denda adat atau singer adat bagi yang melanggar pali atau pantangan dalam ritual tiwah adalah denda menggant dua kali dari biaya tiwah yang telah dikeluarkan oleh anggota pelaksana ritual tiwah. Dalam ritual tiwah biasanya dibuat batas yang boleh dilewati pali dan yang tidak boleh dilewati. Pembatas ini disebut hinting pali, yaitu tali yang diikat dengan daun sawang sebagai pembatas wilayah pali..

\section{UCAPAN TERIMA KASIH}

Para penulis juga mengucapkan terima kasih kepada LP2M Universitas PGRI Palangka Raya yang telah memberikan arahan serta bantuan dalam proses 
penyelesaian penelitian Pali ini, kemudian ucapan terima kasih juga kami berikan kepada Damang kepala adat Jekan Raya kota Palangka Raya Bapak Kardinal Tarung, para Damang, Mantir dan para tokoh adat serta masyarakat Desa Sigi Kecamatan Kahayan Tengah Kabupaten Pulang Pisau, serta yang terakhir ucapan terima kasih kami berikan kepada rekan-rekan dosen di Universitas PGRI Palangka Raya yang tidak bisa kami sebutkan satu persatu.

\section{REFERENSI}

Achmadi, Achmadi. 2016. "Penegakan Hukum Pidana Terhadap Praktek Perjudian Dalam Ritual Tiwah Di Kabupaten Kapuas." Anterior Jurnal I5(2): I8088.

Anwari, Rizki Amalia Nur. 2017. "DAKWAH DAN EKSISTENSI BUDAYA DI TANAH DAYAK." Pp. 205-2014 in Proceeding International Conference On Ethnicity and Globalization, edited by $\mathrm{H}$. Lubis, M. A. Hidayat, and K. Rosyadi. Madura: Universitas Trunojoyo.

Apandie, Chris, and Endang Danial Ar. 2019. "Huma Betang: Identitas Moral Kultural Suku Dayak Ngaju Kalimantan Tengah.” Journal of Moral and Civic Education 3(2):76-91.

Arliman, Laurensius. 2018. "HUKUM ADAT DI INDONESIA DALAM PANDANGAN PARA AHLI." Jurnal Selat 5(2): I77-89.

Bukit, Pilemon. 2019. "Pandangan Kristen Tentang Kebudayaan Dan Adat Istiadat Di Dalamnya." SOTIRIA (Jurnal Theologia Dan Pendidikan Agama Kristen) 2(I):I-I5.

Chakim, Sulkhan. 20I5. "Potret Islam Sinkretisme: Praktik Ritual Kejawen?” Komunika 3(I):I.

Devianty, Rina. 2017. "Bahasa Sebagai Cermin Kebudayaan.” Jurnal Tarbiyah 24(2):226-45.

Dova, Hasven Stama, Hermi Yanzi, and Yunisca Nurmalisa. 2016. "Peranan Tokoh Adat Dalam Mempertahankan Adat Tunggu Tubang Pada Masyarakat Semendo." 4(5):I-I4.

Gunawan, I. Gede Dharman, Pranata, Handoko, Mitro, and Budhi Widodo. 2018. "THE EXISTENCE AND PHILOSOPHY OF TIWAH IN PALANGKA RAYA CITY." Pp. $121-27$ in Proceeding International Conference On Thelogi, Philosophy, and Religion (ICTHEPRES) IHDN, edited by I. K. Donder, I. M. Suwantana, I. M. Redana, and I. D. A. H. Putri. Denpasar: IHDN PRESS.

Hanifi, Muhammad luthfan. 2016. "RITUAL PERANG DALAM KEBUDAYAAN SUKU DAYAK." Jurnal Kajian Kebudayaan II(2):83-87.
Helim, Abdul, and Unggun Tiara Syahriana. 2019. "Keikutsertaan Masyarakat Muslim Dalam Upacara Tiwah Agama Hindu Kaharingan Di Kota Palangka Raya." Al-Qisthu: Jurnal Kajian IlmuIlmu Hukum I7(2):34.

Iban, Carlos, and Tuti Elfrida. 20I7. "ARSITEKTUR RELIGI PESTA TIWAH DAYAK NGAJU SEBAGAI DAYA TARIK WISATA BUDAYA DI KALIMANTAN TENGAH.” ATRIUM 3(2):IOI12.

Inrevolzon. 2013. "Kebudayaan Dan Peradaban Oleh: Inrevolzon." Tamaddun: Jurnal Kebudayaan Dan Sastra Islam I3(2): I-8.

lyon, Firminus. 2018. "LEKSIKON AMAIK DALAM RITUAL NAAH PADI PADA MASYARAKAT DAYAK SALAKO DI KECAMATAN SAJINGAN BESAR SAMBAS." Jurnal Pendidikan Dan Pembelajaran Khatulistiwa 7(3).

Kuenna. 20I5. "Simbol Dalam Upacara Adat Dayak Ngaju (Symbols in Ritual Tribe of Dayak Ngaju)." Jurnal Bahasa, Satra, Dan Pembelajarannya 5(2): 179-87.

Liadi, Fimeir. 2017. "PENELUSURAN SISTEM KEPERCAYAAN SUKU DOHOI (ANAK SUKU OT DANUM) DI TUMBANG SAMBA KABUPATEN KATINGAN KALIMANTAN TENGAH.” 2(2):I29-44.

Moleong, Lexy J. 2012a. Metodologi Penelitian Kualitatif. 30th ed. Bandung: PT. REMAJA ROSDAKARYA.

Moleong, Lexy J. 20I2b. Metodologi Penelitian Kualitatif. 30th ed. Bandung: PT. REMAJA ROSDAKARYA.

Natalia, Desi, Jefry Tarantang, and Ni Nyoman Adi Astiti. 2020. "Makna Manuhir Dalam Kehidupan Masyarakat Dayak Ngaju Di Kota Palangka Raya." Jurnal Studi Agama Dan Masyarakat 16(I):24-34.

Ngare, Ferdinandus. 2014. "Studi Komunikasi Budaya Tentang Upacara Ritual Congko Lokap Dan Komunikasi Dalam Pengembangan Pariwisata Daerah Manggarai Provinsi Nusa Tenggara Timur.” Jurnal J-Ika I(I):40-50.

Norhalisa, Eddy Lion, and Dotrimensi. 2020. "MAKNA SEPUNDU BAGI MASYARAKAT AGAMA HINDU KAHARINGAN." JURNAL PARIS LANGKIS I (I):I5-20.

Pelu, Ibnu Elmi AS, and Jefry Tarantang. 2018. "Interkoneksi Nilai-Nilai Huma Betang Kalimantan Tengah Dengan Pancasila." Jurnal Studi Agama Dan Masyarakat I4(2): I 19.

Sanawiah, and M. Raymon Abdalla. 2017. "HUKUM KEIKUTSERTAAN WARGA DAYAK NGAJU MUSLIM DALAM PELAKSANAAN UPACARA TIWAH ( PERSPEKTIF ULAMA KOTA PALANGKA RAYA ). Oleh: Sanawiah, Dosen 
Universitas Muhammadiyah Palangkaraya Dan.” Jurnal Hadratul Madaniyah 4(I): I8-25.

Saputri, Claudya Ika, Deni Tri Ardianto, Program Studi, Desain Komunikasi, Fakultas Seni, Universitas Kristen Petra, and JI Siwalankerto. 2016. "Perancangan Film Dokumenter Tradisi Keagamaan Upacara Tiwah Suku Dayak Di Kalimantan Tengah.” Jurnal DKV Adiwarna I(8): I7.

Si, Hardin M. 2016. "Komunikasi Transendental Pada Ritual Kapontasu Dalam Sistem Perladangan Masyarakat Etnik Muna." Jurnal Penelitian Komunikasi Dan Opini Publik 20(I):I24I79.

Sugiyono. 2016. Metode Penelitian Kuantitatif, Kualitatif Dam R\&D. 23rd ed. Bandung: ALFABETA CV.

Sukiada, Kadek. 2016. "Dalam Kepercayaan Hindu Kaharingan.” Dharmasmrti: Jurnal Ilmu Agama Dan Kebudayaan 14(27):52-67.

Surya, Willy Herdianto. 2017. "Eksistensi Adat Istiadat Suku Hutan Dalam Kehidupan Sehari-Hari." Aksara Public I (I): I-I4.

Susylawati, Eka. 2013. "Eksistensi Hukum Adat Dalam Sistem Hukum Di Indonesia." Al-lhkam: Jurnal Hukum Dan Pranata Sosial 4(I): 124-40.

Syamsudin, Syamsudin. 2008. "Beban Masyarakat Adat Menghadapi Hukum Negara." Jurnal Hukum lus Quia lustum I5(3):338-5I.

Taufiq, Amal. 20I3. "Perilaku Ritual Warok Ponorogo Dalam Perspektif Teori." Jurnal Sosiologi Islam 3(2): ||3-2|.

Usop, Linggua Sanjaya. 2015. “Usop, Linggua Sanjaya. "Maniring Hinting Sebagai Gerakan Kontra Hegemoni Masyarakat Dayak Dalam Pembertahanan Hak-Hak Atas Tanah Di Kabupaten Kota Waringin Timur." Universitas Udayana.

Wirna, Mujiati. 2018. ANALISIS SEMIOTIKA CHARLES SANDERS PEIRCE PADA TRADISI BUDAYA TIWAH DI DESA BANGKAL KALIMANTAN TENGAH. University of Muhammadiyah Malang.

Yuliana, Yuliana. 2019. "Ritual Adat Hinting Pali Sebuah Resolusi Konflik Alternatif: Strategi Membuka Komunikasi Pada Konflik Tanah Adat Antara Komunitas Adat Tamanggung Doho Dengan Pt Karya Dwi Putera (Pt Kdp) Di Desa Tumbang Marak, Kalimantan Tengah." Jurnal Sosiologi Nusantara 5(2): 157-70. 